\title{
Impact of Prevnar vaccination on nasopharyngeal carriage of Streptococcus pneumoniae in healthy children in New Caledonia
}

\author{
Julie Scotet ${ }^{1 *}$, Francine Baumann ${ }^{1}$, Myrielle Dupont-Rouzeyrol ${ }^{1}$, Catherine Grangeon ${ }^{2}$, Shahin Oftadeh ${ }^{3}$, \\ Benoit Garin', Suzanne Chanteau', Simon Le Hello ${ }^{1}$ \\ From Institut Pasteur International Network Annual Scientific Meeting \\ Hong Kong. 22-23 November 2010
}

We assessed the impact of the heptavalent pneumococcal conjugate vaccine (PCV7) on the nasopharyngeal carriage of Streptococcus pneumoniae in healthy children aged 2 to 24 months, four years after its implementation in New Caledonia. The data were compared with those obtained, before the introduction of the vaccine, in the same target population

From February to October 2008, 592 children were enrolled prospectively, regardless of their vaccinal status. Between 2002 and 2008, the prevalence of the overall pneumococcal carriage and of vaccine type carriage decreased significantly, respectively $52.3 \%$ to $42.1 \%$ ( $p<$ $10^{-3}$ ) and $46.9 \%$ to $22.2 \%\left(p<10^{-3}\right)$. This reduction was offset by an increase (20.8\% to $29.0 \%, p=0.013)$ of the carriage of non-vaccine type pneumococci with reduced susceptibility to penicillin (PRSP), notably the serotypes 15B $(p=0.027)$ and 19A $(p=0.001)$. This increase in PRSP carriage was marked in the Northern Province $(p=0.005)$ and among Melanesian children $(p=0.009)$. Surprisingly this increase was mainly attributed to the vaccine type $19 \mathrm{~F}\left(p<10^{-3}\right)$.

In conclusion, as expected, the PCV7 vaccine led to a decrease of the pneumococcal carriage and the replacement of vaccine strains by non vaccine strains, however increasingly resistant to penicillin. In the Northern Province, the increasing carriage of penicillin resistant 19F strains escaping the vaccine is of concern and justifies a further comprehensive analysis using MLST genotyping.

'Institut Pasteur de Nouvelle-Calédonie, Nouméa, 98800, New Caledonia

Full list of author information is available at the end of the article

\section{Author details}

${ }^{1}$ Institut Pasteur de Nouvelle-Calédonie, Nouméa, 98800, New Caledonia. ${ }^{2}$ Centre Protection Maternelle et Infantile, Nouméa, 98800, New Caledonia. ${ }^{3}$ Pneumococcal Reference Laboratory, Westmead Hospital, Westmead NSW 2145, Australia.

Published: 10 January 2011

\section{doi:10.1186/1753-6561-5-S1-P13}

Cite this article as: Scotet et al: Impact of Prevnar vaccination on nasopharyngeal carriage of Streptococcus pneumoniae in healthy children in New Caledonia. BMC Proceedings 2011 5(Suppl 1):P13.

Submit your next manuscript to BioMed Central and take full advantage of:

- Convenient online submission

- Thorough peer review

- No space constraints or color figure charges

- Immediate publication on acceptance

- Inclusion in PubMed, CAS, Scopus and Google Scholar

- Research which is freely available for redistribution

(0) 2011 Scotet et al; licensee BioMed Central Ltd. This is an open access article distributed under the terms of the Creative Commons
Attribution License (http://creativecommons.org/licenses/by/2.0), which permits unrestricted use, distribution, and reproduction in any medium, provided the original work is properly cited. 